\title{
LEVANTAMENTO DA OCORRÊNCIA DE Xylella fastidiosa EM CAFEEIRO DO DISTRITO FEDERAL E ENTORNO
}

\author{
BERNARDO UENO \& CARLOS H. UESUGI \\ Departamento de Fitopatologia, Universidade de Brasília, Cx. Postal 4457, 70910-900, Brasília, DF, \\ fax: (061) 272-1793, e-mail: berueno@unb.br
}

(Aceito para publicação em 26/10/2001)

Autor para correspondência: Bernardo Ueno

\section{ABSTRACT}

Survey of Xylella fastidiosa occurrence on coffee plants in the Distrito Federal and Vicinity

A survey of the occurrence of Xylella fastidiosa in coffee (Coffea arabica) plants was performed in Distrito Federal and Vicinity properties. Branches of coffee plants "Catuaí" and "Mundo Novo" were collected from five properties and analysed. Bacterial mass was observed by optical microscopy in the xylem contents. Isolation was performed in
BCYE medium and identification was carried out by serological reaction with $X$. fastidiosa specific antigen. Xylella fastidiosa was detected in samples from all the properties. In $95 \%$ of the samples collected, the presence of the bacterium was detected in the xylem contents. This is the first report of the occurrence of $X$. fastidiosa in coffee plants in Distrito Federal and Vicinity.
A ocorrência de Xylella fastidiosa (Wells et al.) é relatada em vários estados, incluindo São Paulo, Paraná e Minas Gerais. A presença de X. fastidiosa em cafeeiro (Coffea arabica L.) (Beretta, M. J. S. et al. Plant Disease $80,821,1996)$ tem preocupado, pois esta bactéria tem causado sérios prejuízos em culturas como ameixeira (Prunus salicina Lindl.), citros [Citrus sinensis (L.) Osbeck] e videira (Vitis vinifera $\mathrm{L}$.), embora ainda não se conheça os danos que possa causar ao cafeeiro. O presente trabalho teve como objetivo fazer o levantamento da ocorrência de X. fastidiosa em cafeeiros do Distrito Federal e Entorno. Amostras de ramos de cafeeiro (com oito a 12 anos) das cultivares Catuaí e Mundo Novo, sem sintoma aparente, foram coletadas em cinco propriedades no período de junho a novembro de 1998 e analisadas quanto à presença de $X$. fastidiosa no conteúdo xilemático através de microscópio ótico. A presença de $X$. fastidiosa foi observada nas amostras de todas as cinco propriedades levantadas (Tabela 1). Isolamentos foram feitos em meio BCYE (Wells, J. M. et al. Appl. Environ. Microbiol 42: $357,1981)$ que resultaram em crescimento de colônias típicas da bactéria. Testes de imunofluorescência indireta com anticorpo específico para $X$. fastidiosa e anti-IgG conjugado com isotiocianato de tetrarodamina (TRITC) confirmaram a presença da bactéria em cafeeiro. Em 95\% das amostras coletadas foi detectada a presença de um grande número de células de $X$. fastidiosa no conteúdo xilemático, observado através de microscopia ótica. Este é o primeiro relato sobre a ocorrência de X. fastidiosa em cafeeiro no Distrito Federal e Entorno (Ueno, B. \& Uesugi, C. H. Summa Phytopathol. 25: 22, 1999).

TABELA 1 - Incidência de Xylella fastidiosa em amostras de ramos de cafeeiro (Coffea arabica) coletados aleatoriamente em propriedades do Distrito Federal e Entorno

\begin{tabular}{lcccc}
\hline \hline Local & Variedade & $\begin{array}{c}\mathbf{N}^{\mathbf{0}} \text { de } \\
\text { Amostras }\end{array}$ & $\begin{array}{c}\text { Amostras } \\
\text { positivas }\end{array}$ & $\begin{array}{c}\text { Total de } \\
\text { plantas }\end{array}$ \\
\hline Faz. 1 $^{\mathrm{a}}$ & Mundo Novo & 6 & 6 & 250.000 \\
Faz. 1 & Catuaí & 6 & 4 & -- \\
Faz. 2 & Mundo Novo & 8 & 2 & 150.000 \\
Faz. 3 & Mundo Novo & 6 & 6 & 5.000 \\
Faz. 3 & Catuaí & 4 & 3 & 40.000 \\
Faz. 3 & Catuaí & 10 & 10 & 111.000 \\
Faz. 4 & Mundo Novo & 6 & 6 & 200.000 \\
Faz. 4 & Catuaí & 6 & 6 & 200.000 \\
Faz. 5 & Mundo Novo & 8 & 8 & 90.000 \\
Faz. 5 & Catuaí & 9 & 9 & 60.000 \\
\hline${ }^{a}$ Fazenda 1; ${ }^{\text {N }}$ Número de plantas cultivadas na propriedade.
\end{tabular}

